\title{
Galantamine improved cognition and global functioning in vascular dementia or Alzheimer's disease with cerebrovascular disease
}

Erkinjuntti T, Kurz A, Gauthier S, et al. Efficacy of galantamine in probable vascular dementia and Alzheimer's disease combined with cerebrovascular disease: a randomised trial. Lancet 2002 Apr 13;359:1283-90.

\author{
QUESTION: In patients with probable vascular dementia or Alzheimer's disease (AD) \\ with cerebrovascular disease, is galantamine more effective than placebo for improving \\ cognitive ability and global functioning?
} Source of funding:
not stated.

For correspondence: Dr T Erkinjuntti Helsinki University Central Hospital, Helsinki, Finland. Email

timo.erkinjuntti@hus.fi.

\section{Design}

6 month randomised (unclear allocation concealment*), blinded (clinicians and patients),* placebo-controlled trial.

\section{Setting}

Canada, Denmark, Finland, France, Germany, Ireland, Israel, The Netherlands, Poland, and the UK.

\section{Patients}

592 patients (mean age 75 y, 53\% men) who met clinical criteria for probable vascular dementia or possible $\mathrm{AD}$ with radiological evidence of cerebrovascular disease. Additional inclusion criteria included a score of 10 to 25 on the Mini-Mental State Examination and $\geq 12$ on the Alzheimer Disease Assessment Scale Cognitive subscale (ADAS-COG). Exclusion criteria included evidence of neurodegenerative disorders other than $\mathrm{AD}$ that might cause or contribute to dementia, and cognitive impairment resulting from cerebral trauma. Follow up was $82 \%$ and $77 \%$ at 3 and 6 months, respectively.

\section{Intervention}

Patients were allocated to receive galantamine, $24 \mathrm{mg} /$ day $(n=396)$ or placebo $(n=196)$ once daily for 6 months.

\section{Main outcome measures}

Cognitive ability measured by the standard 11 item ADAS-COG (ADAS-COG11) and global functioning measured by the Clinician's Interview-Based Impression of Change plus caregiver input assessed at baseline and 3 and 6 months.

\section{Main results}

At 6 months, improvement in cognitive ability was greater in the galantamine group than in the placebo group. More patients in the galantamine group remained stable or had improved global functioning at 6 months. More patients in the galantamine group than in the placebo group withdrew from the study because of adverse effects $(20 \%$ v $8 \%, p<0.01)$.

\section{Conclusion}

In a mixed population of patients with probable vascular dementia or Alzheimer's disease and cerebrovascular disease, galantamine was more effective than placebo for improving cognitive ability and global functioning. *See glossary.
Galantamine v placebo for probable vascular dementia or Alzheimer's disease combined with cerebrovascular disease at 6 monthst

\begin{tabular}{lllll}
\hline Outcome & Galantamine & Placebo & Difference (95\% Cl) \\
$\begin{array}{l}\text { Mean change in ADAS-COG11 } \\
\text { scores from baseline }\end{array}$ & -1.7 & 1.0 & $2.7(1.4$ to 4.0$) \ddagger$ & \\
$\begin{array}{c}\text { Patients with improvement or } \\
\text { no change on CIBIC-plus }\end{array}$ & $74 \%$ & $59 \%$ & $25 \%(9$ to 47$)$ & $7(5$ to 17$)$ \\
\hline
\end{tabular}

†ADAS-COG11 = standard 11 item Alzheimer Disease Assessment Scale cognitive subscale, CIBIC-plus = Clinician's Interview-Based Impression of Change plus caregiver input. Other abbreviations defined in glossary; RBI, NNT, and $\mathrm{Cl}$ calculated from data in article.

$\ddagger$ The difference favours galantamine.

\section{COMMENTARY}

Acetylcholinesterase inhibitors are thought to partially correct the cholinergic deficit characteristic of $\mathrm{AD}$. Benefits from these drugs are described as short term improvement or lack of decline in cognitive function. In this study by Erkinjuntti $e t$ al of older patients with vascular dementia and $\mathrm{AD}$ combined with cerebrovascular disease, about one-third (35.3\%) of patients on galantamine compared with about one-fifth (22.2\%) of patients on placebo improved by $\geq 4$ points on a scale (ADAS-COG11) commonly used in $\mathrm{AD}$ drug trials. Patients with $\mathrm{AD}$ were most likely to improve.

Adverse events (predominately nausea and vomiting) caused one-fifth (20\%) of patients in the galantamine group to discontinue the drug. Erkinjuntti et al recommend a different dose escalation regimen to minimise this complication, but gastrointestinal toxicity, common to cholinesterase inhibitors, has to be weighed against the potential benefits of galantamine. Interpretation of this study is further complicated because more patients in the galantamine group than in the placebo group were taking antispasmodics and anticholinergics (domperidone $5 \%$ v 1\%, and metoclopramide 3\% $v 0 \%$ ) at baseline-a curious difference possibly relevant to the study outcome, which is left unexplained in the published paper.

This study confirms that such acetylcholinesterase inhibitors as galantamine probably have beneficial effects in some patients with $\mathrm{AD}, \mathrm{AD}$ mixed with cerebro vascular disease, or clinically diagnosed vascular dementia. Recent pathologic studies have shown that $\mathrm{AD}$ mixed with other causes of dementia is common in older people in the community. ${ }^{1-2}$ Whether the benefits outweigh the adverse effects is best assessed in single patient trials using patient-and caregiver-valued clinical end points. ${ }^{3}$ Some patients may experience clinically meaningful improvement, but most will not.

Eric Larson, MD, MPH University of Washington Medical Center Seattle, Washington, USA

1 Lim A, Tsuang D, Kukull W, et al. Clinico-neuropathological correlation of Alzheimer's disease in a community-based case series. J Am Geriatr Soc 1999; 47:564-9.

Snowden DA, Greiner LH, Mortimer JA, et al. Brain infarction and the clinical expression of Alzheimer's disease: the Nun Study. JAMA 1997;277:813-7.

Larson EB, Ellsworth AJ, Oas J. Randomized clinical trials in single patients during a 2-year period. JAMA 1993;270:2708-12. 